\title{
Molecular Study of Glycoprotein (G) Gene Region of Rabies Virus from Spotted Deer, Delhi, India
}

\author{
Girraj Singh', M Chhabra $^{2}, \underline{\text { P Singh }}{ }^{3}, \underline{\text { NK Gupta }}, \underline{\text { M Singhai }}{ }^{5}, \underline{\text { AC Dhariwal }}^{6}, \underline{\text { S Ram }}^{7}$ \\ 1,2,3,4,5,6 National Centre for Disease Control, Delhi, India. \\ ${ }^{7}$ School of Biotechnology, Gautam Buddha University, Greater Noida, GautamBudh Nagar, U.P., India. \\ DOI: https://doi.org/10.24321/0019.5138.201817
}

\begin{abstract}
Rabies is a viral zoonotic disease of public health importance in India. The disease is usually transmitted by a rabid animal bite, scratches and licks on broken skin and mucous membrane. Rabies is reported from all continents except Antarctica although prevalence is more in Asia and Africa. India is endemic for rabies virus (RABV) throughout the country except for islands of Lakshadweep, Andaman \& Nicobar. In the present study, brain samples of clinically suspected animals obtained during the RABV outbreak at National Zoological Park, New Delhi, India, in 2016 were initially tested for rabies antigen by DFAT. All the 32 DFAT positive brain samples were then processed for RNA isolation. The extracted RNA was amplified for glycoprotein (G) gene of 590 bp by RT-PCR followed by nucleotide sequencing. Nucleotide alignment revealed only substitutions without any insertion or deletion. Amino acid alignment revealed replacement at four positions namely L244I, T264A, M310I and N375K. The amino acid change at position where Leucine is replaced by Isoleucine has not been observed in available RABV references of the $G$ gene region either from India or other countries. This mutation was observed in all the samples included in the present study. A phylogenetic tree showed that all the study sequences belonged to Arctic like 1a lineage, in RABV genotype 1 . In conclusion, RABV in the study region is acquiring genetic variation; which may have effect on the pathogenicity. This indicates that continued molecular surveillance of the circulating rabies virus strains should be carried out.
\end{abstract}

Keywords: G gene, Molecular epidemiology, Mutation, Phylogenetic analysis, Rabies virus

\section{Introduction}

Rabies is an acute viral disease which affects the central nervous system of humans and other mammals; although all warm-blooded animals are prone to rabies virus (RABV) infection. ${ }^{1}$ The virus is found in infected wild and some domestic animals, and is transmitted to other animals and to humans through their saliva by bites, scratches, licks on broken skin and mucous membrane. The transmission of RABV is different in sylvatic and urban cycle. The sylvatic cycle involves wildlife species like skunks, racoons, foxes and mongoose while urban cycle of rabies is mainly between rabid stray dogs to domestic animals and humans. ${ }^{2}$ Timely and appropriate rabies post-exposure prophylaxis (PEP) including appropriate wound care followed by administration of rabies immunoglobulin and anti-rabies vaccine is effective in prevention of rabies in humans., ${ }^{3,4}$

The disease is prevalent in more than 150 countries of all continents except Antarctica. But it is endemic in Asian and African continents. India and its neighboring countries like Pakistan and Bangladesh have prevalence of RABV

Corresponding Author: Dr. M Chhabra, National Centre for Disease Control, Delhi, India.

E-mail Id: malachhabra@yahoo.co.in

Orcid Id: https://orcid.org/0000-0003-2328-9583

How to cite this article: Singh G, Chhabra M, Singh P et al. Molecular Study of Glycoprotein (G) Gene Region of Rabies Virus from Spotted Deer, Delhi, India. J Commun Dis 2018; 50(3): 28-35. 
in almost whole of the territory with a stable pattern reporting thousands of human deaths every year. Rabies virus is responsible for 55,000 human deaths per year globally while in Asia 32,000 human deaths per year are reported. ${ }^{5}$ In India, estimated 20,000 human deaths occur yearly due to rabies. ${ }^{6}$

Rabies virus belongs to genus Lyssavirus and family Rhabdoviridae. It is a bullet shaped structure having180 $\mathrm{nm} \times 75 \mathrm{~nm}$ dimensions. ${ }^{7}$ It is non-segmented negativesense RNA genome which is single-stranded and approx. $12 \mathrm{~kb}$ long. ${ }^{8} \mathrm{RABV}$ encodes five viral proteins in the order of 3'-N-P-M-G-L-5', named as nucleoprotein, phosphoprotein, matrix protein, glycoprotein, and RNA-dependent RNA polymerase respectively. ${ }^{9-11}$ The RABV glycoprotein envelope is encoded by the $\mathrm{G}$ gene. It is transmembrane protein of type-I having trimeric structure. G protein has three regions; endodomain, transmembrane and ectodomain. It is responsible for receptor binding and viral invasion into host cells and plays an important role in pathogenicity. ${ }^{12-16}$ $\mathrm{G}$ gene of RABV has important role in viral pathogenesis, neurovirulence and host adaptation. ${ }^{17-19}$ Phylogenetical and genetic heterogenetical studies based on $\mathrm{G}$ gene of RABV are available from many countries however, very few studies are reported from India. ${ }^{18,20-24}$ The present study was undertaken for phylogenetic and mutational analysis of $G$ gene region of RABV on the brain samples of animals obtained during the RABV outbreak at National Zoological Park, New Delhi, India in 2016.

\section{Materials and Methods}

\section{Samples}

Fifty-two brain samples of different animals (spotted deer n-50; sambar deer n-1 and squirrel n-1) that died of rabies like symptoms at National Zoological Park, New Delhi were referred to WHO Collaborating Center for Rabies Epidemiology, National Centre for Disease Control, Delhi, India during the period from April to August 2016.

\section{Rabies Diagnosis}

All 52 samples were tested by Direct fluorescent antibody test (DFAT) using rabies anti-nucleocapsid conjugate (BioRad). This is a gold-standard test approved by the World Health Organization (WHO) and World Organization for Animal Health (OIE) for rabies diagnosis. ${ }^{25}$

\section{RNA Extraction}

A $10 \%$ (weight/volume) homogenate of the brain tissue of DFAT positive samples were prepared by using sterile phosphate-buffered saline (PBS). TRIZOL was added for lysis and the RNA was extracted using a commercial kit QI Amp viral RNA Mini kit (Qiagen, Germany). The final elution of RNA was done by $50 \mu \mathrm{L}$ of elution buffer (provided in the kit).

\section{Reverse Transcription-Polymerase Chain Reaction (RT-PCR)}

The amplification of $\mathrm{G}$ gene fragment of 590-bp of RABV was carried out using one step RT-PCR kit (Qiagen, Germany) on ABI 9700 Thermal cycler (Applied Biosystems, USA) using primers Gp2L (5'-AGT AGA GGG AAG AGA GCATCC A-3') and Gp2P (5'-GAG GAT AGG AAC AAC TCCAT-3'). ${ }^{26}$ The thermal profile for the amplification was as follows: first cycle of reverse transcription at $50^{\circ} \mathrm{C}$ for $30 \mathrm{~min}$, followed by initial denaturation at $95^{\circ} \mathrm{C}$ for $15 \mathrm{~min}$; 35 cycles of denaturation at $95^{\circ} \mathrm{C}$ for $30 \mathrm{~s}$, annealing at $62^{\circ} \mathrm{C}$ for $30 \mathrm{~s}$, and elongation at $72^{\circ} \mathrm{C}$ for $1 \mathrm{~min}$ and a final extension at $72^{\circ} \mathrm{C}$ for $10 \mathrm{~min}$. The amplified PCR products (590-bp) were run in ethidium bromide $(0.5 \mu \mathrm{g} / \mathrm{mL})$ stained $1.2 \%$ agarose gel and were visualized under UV transilluminator (Gel Documentation System, Alpha Imager EC, USA). Purification of PCR products for sequencing was done using the QIA quick PCR purification kit (Qiagen, Germany).

\section{Sequencing and Phylogenetic Analysis}

An ABI 3130xl automated capillary DNA sequencer (Applied Biosystems) was used to perform automated nucleotide sequencing using the Big Dye Terminator Cycle Sequencing ready reaction kit v3.1 (Applied Biosystems, USA). Alignment, cleaning and analyzing of sequences were carried out on BioEdit Sequence Alignment Editor Version 7.2. ${ }^{27}$ All study sequences were aligned and compared with PV strain of RABV (M13215). BLAST search (www. ncbi.nlm.nih.gov/Education/BLASTinfo/information3.html) was carried out to confirm the identity of strains. The sequences were submitted to GenBank (www.ncbi.nlm.nih. gov) and accession numbers were obtained. Phylogenetic analysis was carried out using molecular evolutionary genetics analysis (MEGA), software version 7.0 (http:// www.megasoftware.net/). The study sequences and other rabies virus sequences that were retrieved from GenBank were used for the construction of phylogenetic tree by using neighbor joining (NJ) method with bootstrap value of 1000 replications (Table 1). All deduced amino acid sequences of $G$ gene region of RABV were analyzed and compared with PV strain and other representative RABV isolates from India and other parts of the world for variation(s). 
Table 1.Details of rabies and rabies related virus isolates used for phylogenetic analysis

\begin{tabular}{|c|c|c|c|c|c|}
\hline S. No. & Virus reference & Host & Place of origin & Year & Accession No. \\
\hline $\begin{array}{c}1 \text { to } \\
32\end{array}$ & $\begin{array}{c}\text { 01/IRV/NCDC to 32/IRV } \\
\text { NCDC }\end{array}$ & Spotted deer & Delhi & 2016 & $\begin{array}{l}\text { MF375722 to } \\
\text { MF375753 }\end{array}$ \\
\hline 33 & IRV12-RS & Sambar deer & Delhi & 2013 & KM278994 \\
\hline 34 & IRV10-RHB & Himalayan black bear & Delhi & 2013 & KM278992 \\
\hline 35 & IRV11-RM & Mongoose & Delhi & 2013 & KM278993 \\
\hline 36 & IUP-R198 & Horse & Uttar Pradesh & 2012 & KF150745 \\
\hline 37 & rv61 & Human & UK-India & 1987 & JQ685981 \\
\hline 38 & UK_from-India & Human & India & 2010 & GU936881 \\
\hline 39 & 3878-78(11008NEP) & Goat & Nepal & 2010 & JX944593 \\
\hline 40 & IAP-R191 & Dog & Andhra Pradesh & 2009 & KF150738 \\
\hline 41 & IRV1-RD & Dog & Uttar Pradesh & 2001 & KM492746 \\
\hline 42 & Pk23 & Cattle & Pakistan & 2010 & HE802675 \\
\hline 43 & IRV5-RH & Hyena & Rajasthan & 2010 & KM408747 \\
\hline 44 & IRV8-RC & Cattle & Uttar Pradesh & 2013 & KM492751 \\
\hline 45 & IMA-R189 & Human & Maharashtra & 2009 & KF150736 \\
\hline 46 & IAP-R195 & Human & Andhra Pradesh & 2011 & KF150742 \\
\hline 47 & IRV2-RD & Dog & Madhya Pradesh & 2002 & KM492748 \\
\hline 48 & IRV3-RC & Cattle & Gujarat & 2008 & KM492747 \\
\hline 49 & Germany_Trp-India & Human & Germany-India & 2005 & AY956319 \\
\hline 50 & IRV23-RD & Dog & Karnataka & 2014 & KM492763 \\
\hline 51 & IKE-R109 & Dog & Kerala & 2004 & KF150722 \\
\hline 52 & 3878-09(11009 NEP) & Dog & Nepal & 2010 & JX944586 \\
\hline 53 & BDR7 & Cattle & Bangladesh & 2007 & AB699213 \\
\hline 54 & 02052AFG & Dog & Afghanistan & 2002 & JX987718 \\
\hline 55 & Pk24 & Cattle & Pakistan & 2007 & HE802676 \\
\hline 56 & 9104USA (CRBIP8.32) & Skunk & USA & 1991 & JX987749 \\
\hline 57 & 91RABN3899 & Skunk & Canada & 1991 & U11743 \\
\hline 58 & NeiMeng927B & Raccoon dog & China & 2007 & EU284096 \\
\hline 59 & SKRRD9903YG & Raccoon dog & South Korea & 1999 & DQ076099 \\
\hline 60 & CVS & - & - & & GQ918139 \\
\hline 61 & MEX1-DG & Dog & Mexico & 1991 & AF325477 \\
\hline 62 & CHAND03 & Dog & India & 1999 & AY987478 \\
\hline 63 & PV & - & - & & M13215 \\
\hline 64 & 92RBG1741_Canada & Skunk & Canada & 1992 & AF344305 \\
\hline 65 & POL2-HM & Human & Poland & 1985 & AF325465 \\
\hline 66 & 9147FRA & Fox & France & 1991 & EU293115 \\
\hline 67 & 96321IRA & Jackal & Iran & 1996 & JX987734 \\
\hline 68 & HUN1-FX & Human & Hungary & 2001 & AF325462 \\
\hline 69 & 8805CAM & Unknown & Cameroon & 1988 & AF325481 \\
\hline 70 & ITN-R148 & Dog & Tamil Nadu & 2005 & KF150733 \\
\hline 71 & IKE-R154 & Elephant & Kerala & 2005 & KF150734 \\
\hline 72 & H-08-1320_SRL & Human & Sri Lanka & 2008 & AB569299 \\
\hline
\end{tabular}




\begin{tabular}{|c|c|c|c|c|c|}
\hline 73 & NEP1-DG & Dog & Nepal & 2000 & AF325489 \\
\hline 74 & F01 & Fferret badger & China & 2008 & FJ825133 \\
\hline 75 & Hubei/Wuhan/070308 & buffalo & China & 2007 & EF643518 \\
\hline 76 & IMDRV-13 & Damadama (fallow deer) & China: Inner Mongolia & 2013 & KJ564280 \\
\hline 77 & 03003INDO & Dog & Indonesia & 2003 & EU086151 \\
\hline 78 & 04030PHI & Human & Philippines & 2004 & EU086155 \\
\hline 79 & $9913 B I R$ & Dog & Myanmar & 1999 & EU086129 \\
\hline 80 & MAL1-HM & Human & Malaysia & 1985 & AF325487 \\
\hline 81 & THAI1-HM & Human & Thailand & 1983 & AF325488 \\
\hline 82 & $9910 L A O$ & Dog & Laos & 1999 & EU086152 \\
\hline 83 & $9908 C B G$ & Dog & Cambodia & 1999 & EU086130 \\
\hline 84 & 01016VNM & Dog & Vietnam & 2001 & EU086159 \\
\hline 85 & NY771_Canada & Raccoon & USA & 1981 & AF325494 \\
\hline 86 & USA8-BT & Bat & Argentina & 1997 & EU293116 \\
\hline 87 & 9704ARG_Bat & Bat & Australia & 1997 & AF006497 \\
\hline 88 & ABL-AUS_Bat & Bat & Holland & 1986 & AF298145 \\
\hline 89 & EBL2-HOL_Bat & Bat & Poland & 1985 & AF298142 \\
\hline 90 & EBL1-POL_Bat & Bat & South Africa & 1981 & AF298147 \\
\hline 91 & Duv2-SAF_Bat & Bat & Nigeria & 1956 & AF298148 \\
\hline 92 & Lag-NGA_Bat & Bat & Ethiopia & 1990 & U17064 \\
\hline 93 & Mok-ETH_Cat & Cat & &
\end{tabular}

\section{Results}

In the present study, of the 52 samples, 32 brain samples of spotted deer were found positive for rabies antigen by DFAT. The $\mathrm{G}$ gene of 590bp of RABV was also detected in all the 32 DFAT positive brain samples by RT-PCR. These were sequenced and confirmed by BLAST search. The sequences were submitted to GenBank and accession numbers were obtained (MF375722 - MF375753). All 32 studied nucleotides sequences did not depict any insertion or deletion however, substitutions were noted. The study sequences shared $99.6-100 \%$ nucleotide identity among themselves. 


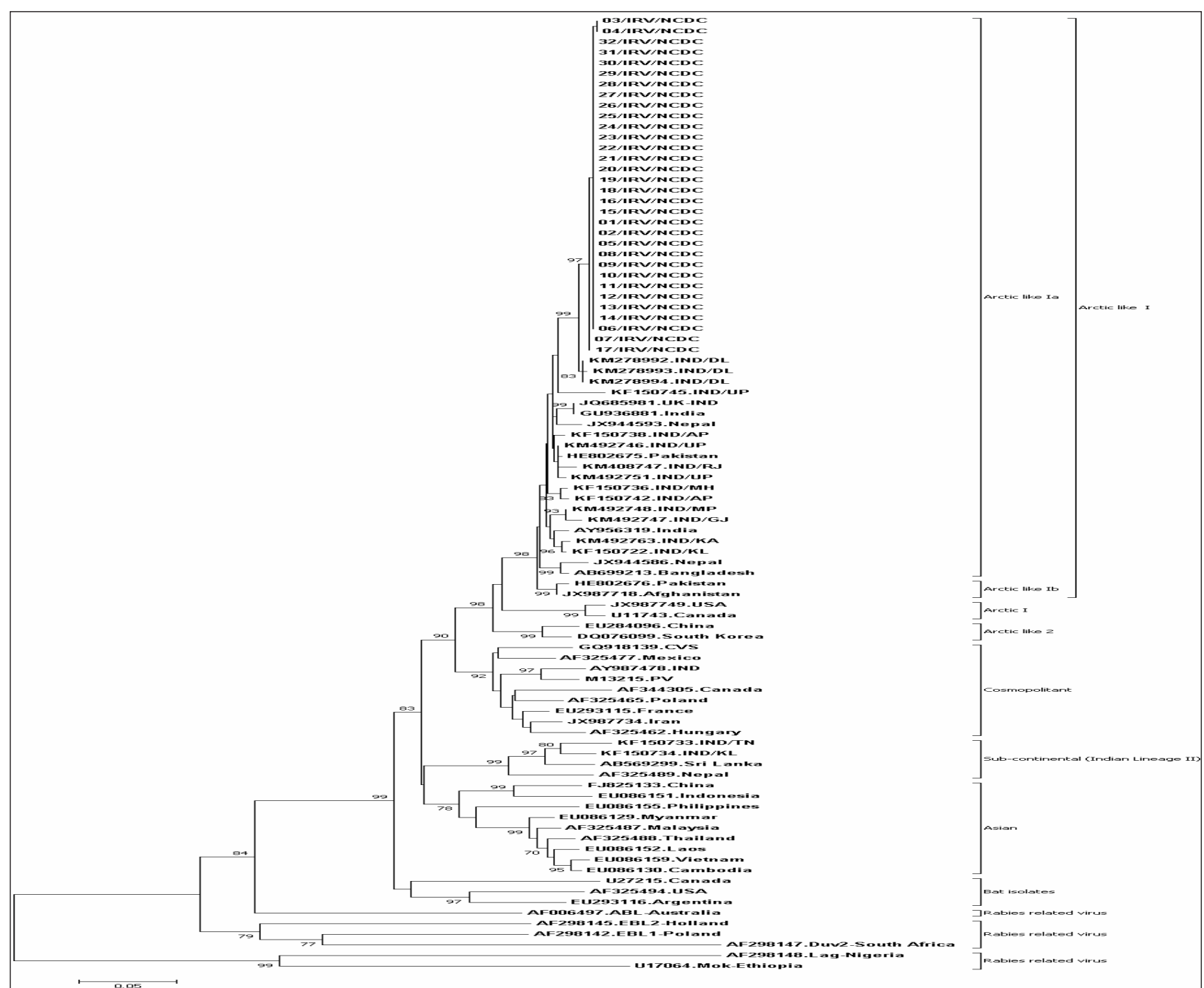

Figure 1.Phylogenetic tree of RABV based on 519-bp nucleotide sequences of the $G$ gene generated by the neighbor-joining method. Bootstrap support values (based on 1000 replications) above $70 \%$ are shown at the branch nodes. Naming scheme is accession number followed by name of country. RABV samples sequenced in the study are shown by virus reference ID

All 32 study sequences of $G$ gene region were aligned together with 61 reference sequences of rabies and rabiesrelated virus. These 61 reference sequences belonged to 19 animals' species from 32 countries including 10 from previously submitted from India (Table 1$)$. The NeighborJoining (NJ) tree was used to infer the phylogenetic relationships of these sequences. The phylogenetic tree revealed that all the study sequences were in close proximity to the sequence of RABV reported from Delhi in2013 (KM278992, KM278993 \& KM 278994) and belonged to Arctic like 1 a lineage in RABV genotype 1 (Figure 1 ). Sequences of other Indian states viz. Uttar Pradesh, Andhra Pradesh, Rajasthan, Madhya Pradesh, Gujarat, Karnataka, Kerala and neighboring countries like Pakistan, Bangladesh and Nepal also belonged to Arctic like 1a clade. 


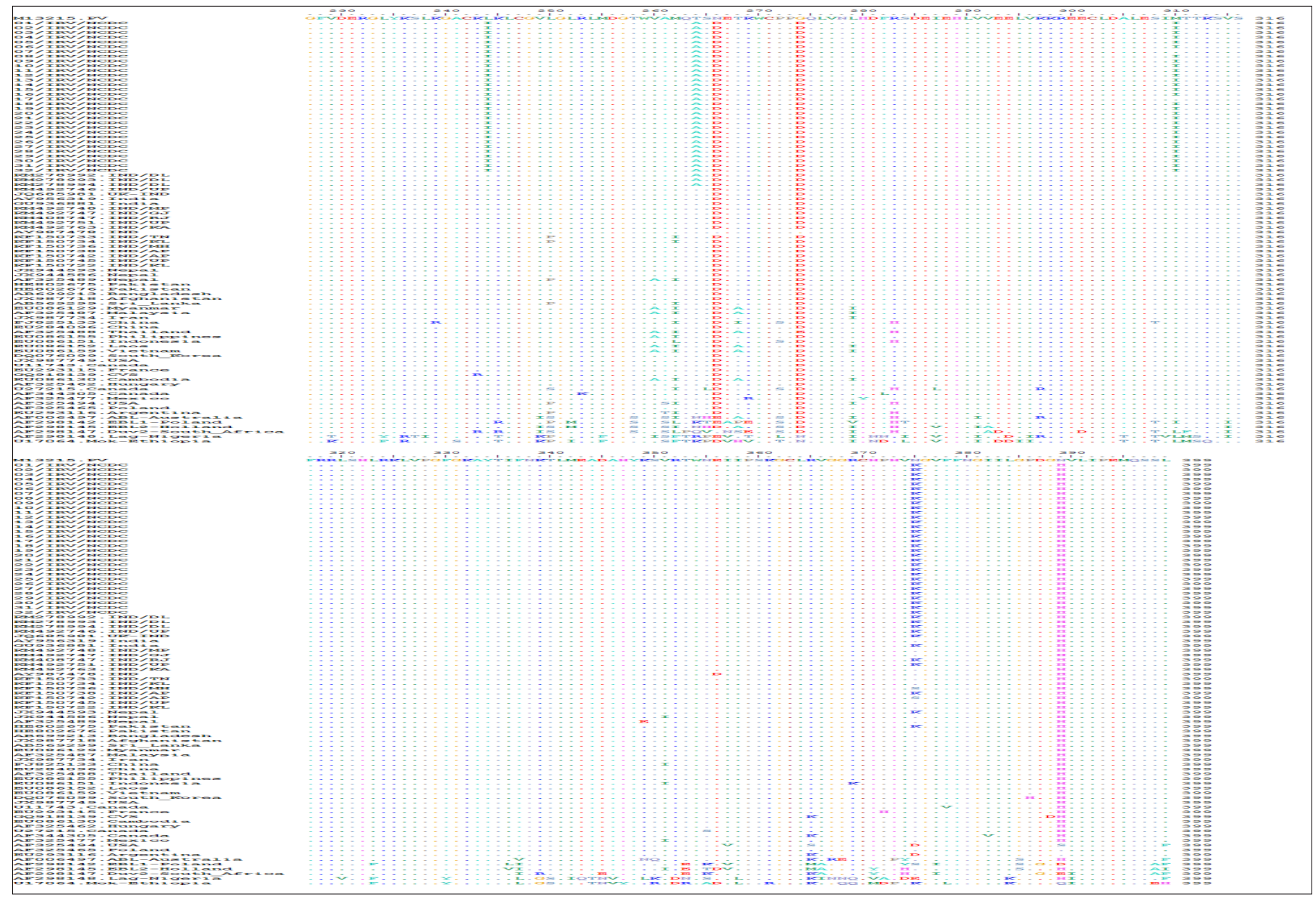

Figure 2.Amino acid sequence of $G$ gene of Indian rabies virus isolates obtained after alignment with rabies virus and rabies related virus of other parts of the world. Differences from the PV sequence are indicated, and dots represent identity at that position

The deduced amino acid sequence of $G$ gene region of all 32 study isolates were compared with PV strain of RABV (M13215) and other representative isolates (Figure 2). All 32 study amino acid sequences showed 99.42-100\% identity among themselves. The amino acid replacement as compared to PV strains occurred at 7 positions viz. L244I, T264A, N266D, G274D, M310I, N375K and N389H in our study. However, as compared to other representative isolates amino acid replacement occurred at four positions viz. L244I, T264A, M310I, and N375K. The amino acid change from leucine to isoleucine $(\mathrm{L} \rightarrow \mathrm{I})$ was observed at position 244 in all studied samples. This has not been reported earlier. The amino acid change at position 264 from threonine to alanine $(T \rightarrow A)$ was observed in our samples and in the three (KM278992, KM278993 \& KM 278994) sequences reported from Delhi in 2013. Amino acid sequences of earlier RABV strain from Delhi exhibited 98.8-99.2\% identity with our study sequences. The amino acid change methionine to isoleucine $(M \rightarrow I)$ at position 310 occurred in 30 study samples (excluding : two study isolates; 17/IRV/NCDC, 07/IRV/NCDC) and one Poland sample having accession number (AF298142). The amino acid replacement from asparagine to lysine ( $\mathrm{N} \rightarrow$ K) at position 375 occurred in all studied samples. This replacement is also found in isolates from other Indian states like Delhi, Rajasthan, Uttar Pradesh and Andhra Pradesh and neighboring countries isolates like Nepal (JX944593) and Pakistan (HE802675).

\section{Discussion}

Rabies is endemic in India. It is a serious public health concern. It is one of the oldest and most important zoonotic diseases in our country. The RABV outbreak in spotted deer occurred at National Zoological Park, New Delhi, India, in 2016, due to which mass mortality was recorded. The main objective of this study was to do the phylogenetic and mutational analysis of $\mathrm{G}$ gene region of RABV in the brain samples of rabid animals. The $G$ gene of RABV has crucial role in viral tropism, host adaptations, pathogenicity and neuro-virulence. ${ }^{13-17}$ The RABV glycoprotein also has main role in receptor recognition and membrane fusion. ${ }^{12,28}$ Therefore, study of RABV glycoprotein is very important for mutational analysis, genetic heterogeneity and phylogenetic analysis.

In the present study, 32 brain samples of spotted deer were found positive by DFAT and RT-PCR. Phylogenetic analysis of $\mathrm{G}$ gene region of studied RABV isolates revealed that they belonged to Arctic like 1a lineage in RABV genotype I. In the phylogenetic tree, the studied RABV sequences 
were placed closely with three Delhi sequences of the year 2013 and showed maximum relatedness. The circulation of RABV genotype I and Arctic like 1a lineage has been reported from Delhi and other parts of India previously. ${ }^{23,}$ 24,29 The findings of phylogenetic study of $\mathrm{G}$ gene region are in concordance with previous studies and revealed that RABV isolates do not cluster on host species but they cluster on the basis of geographical regions. ${ }^{21,30,31}$ The referred sequences from the neighboring countries like Pakistan, Nepal and Bangladesh were also placed in the Artic like 1 a lineage, which indicates that same RABV strain is circulating in India and its boundary sharing countries. ${ }^{22}$ The tree topology also indicated that all Indian RABV isolates belonged to three different lineages viz. Arctic-like 1, subcontinental and cosmopolitan, though arctic-like 1 lineage is the foremost lineage in the country. However, all the Indian RABV isolates (both studied and referred) were phylogenetically different from the RABV reported from Canada, USA, Argentina and other regions of the world.

It has been reported earlier that the replacement of amino acids in glycoprotein of RABV can alter the pathogenicity of virus. ${ }^{32,33}$ In the present study, amino acid replacement viz. L244I, T264A, M310I, N375K were recorded. The amino acid replacement from leucine to isoleucine $(L \rightarrow I)$ at position 244 of $\mathrm{G}$ gene was found in all samples in our study. This amino acid change has not been observed in available RABV references either from India or other countries.

The amino acid change T264A was also found in three RABV sequences of Delhi from the year 2013 viz. KM278992, KM278993 \& KM 278994. ${ }^{23}$ These three isolates shared maximum identity of $98.8-99.2 \%$ and $98.8-99.4 \%$ with study isolates at nucleotide and amino acid level respectively. The occurrence of T264A in 2013 and 2016 RABV samples of Delhi region revealed the consistent presence of this amino acid replacement. This amino acid replacement can be used as a marker for RABV isolates from Delhi region of India. The RABV from Delhi acquired two amino acid replacement viz. L244I in 2013 and T264A in 2016, signifies that RABV in this region is attaining genetic variation.

The amino acid change $\mathrm{M} 310 \mathrm{l}$ was observed in 30 out of 32 studied samples. This amino acid replacement was reported in one rabies related virus isolate from Poland having accession number AF298142. ${ }^{26}$ The amino acid replacement N375K was found in all studied sequences and Delhi sequences of the year 2013 and other Indian states like Uttar Pradesh, Andhra Pradesh and Rajasthan. This is also exhibited in neighboring countries isolates like Nepal (JX944593) and Pakistan (HE802675). Thus, the presence of N375K is consistent in Indian and neighboring countries RABV isolates.

\section{Conclusion}

Thirty two brain samples of suspected spotted deer were confirmed positive for RABV infection by DFAT test and RT-PCR of $G$ gene region. Phylogenetic analysis indicated that studied sequences belonged to Arctic like 1a lineage in RABV genotype-1. Studied sequences showed maximum relatedness with earlier RABV isolates of Delhi from the year 2013. Amino acid alignment revealed presence of four non-synonymous mutations namely: L244I, T264A, M310I, and N375K; of these L244I was observed only in the present study. This is not accessible in RABV references either from India or other countries. RABV of Delhi region showed genetic variations within the studied $G$ gene region by acquiring amino acid replacements. The mutated RABV strain was the etiological agent of rabies outbreak in animals at National Zoological Park, New Delhi in 2016. Further detailed studies are required to explain the functionality of amino acids variations which may have effect on the pathogenicity. The study indicates that continued molecular surveillance of the circulating rabies virus strains should be carried out.

\section{Conflict of Interest: None}

\section{References}

1. Cisterna D, Bonaventura R, Caillou S, et al. Antigenic and molecular characterization of rabies virus in Argentina. Virus Res 2005; 109(2): 139-47.

2. King A, Turner G. Rabies: a review. Journal of Comparative Pathology 1993; 108(1): 1-39.

3. Shantavasinkul P, Tantawichien T, Wilde $\mathrm{H}$, et al. Postexposure rabies prophylaxis completed in 1 week: preliminary study. Clin Infect Dis 2010; 50(1): 56-60.

4. Shantavasinkul P, Wilde H. Postexposure prophylaxis for rabies in resource-limited/poor countries. Adv Virus Res 2011; 79: 291-307.

5. Sugiyama $\mathrm{M}$, Ito $\mathrm{N}$. Control of rabies: epidemiology of rabies in Asia and development of new-generation vaccines for rabies. Comparative Immunology, Microbiology and Infectious Diseases 2007; 30(5): 273-86.

6. Sudarshan MK, Madhusudana SN, Mahendra BJ, et al. Assessing the burden of human rabies in India: results of a national multi-center epidemiological survey. Int $J$ Infect Dis 2007; 11(1): 29-35.

7. Davies MC, Englert ME, Sharpless GR, et al. The electron microscopy of rabies virus in cultures of chicken embryo tissues. Virology 1963; 21: 642-51.

8. Bourhy H, Kissi B, Tordo N. Molecular diversity of the Lyssavirus genus. Virology 1993; 194(1): 70-81.

9. Albertini AA, Ruigrok RW, Blondel D. Rabies virus transcription and replication. Advances in Virus Research 2011; 79(1): 1-22.

10. Tordo N, Kouknetzoff A. The rabies virus genome: an overview. Onderstepoort J Vet Res 1993; 60(4): 263-9.

11. Shimizu K, Ito N, Mita T, et al. Involvement of nucleoprotein, phosphoprotein, and matrix protein 
genes of rabies virus in virulence for adult mice. Virus Res 2007; 123(2): 154-60.

12. Thoulouze MI, Lafage $M$, Schachner $M$, et al. The neural cell adhesion molecule is a receptor for rabies virus. J Virol 1998; 72(9): 7181-90.

13. Seif I, Coulon P, Rollin PE, et al. Rabies virulence: effect on pathogenicity and sequence characterization of rabies virus mutations affecting antigenic site III of the glycoprotein. J Virol,, 1985; 53(3): 926-34.

14. Kinjiro M, Craig DH, Sergei S, et al. Pathogenicity of different rabies virus variants inversely correlates with apoptosis and rabies virus glycoprotein expression in infected primary neuron cultures. Journal of Virology 1999; 73(1): 510-8.

15. Milosz F, Marie-Luise F, Amy $P$, et al. A single amino acid change in rabies virus glycoprotein increases virus spread and enhances virus pathogenicity. Journal of Virology 2005; 79(22): 14141-8.

16. Dietzschold B, Wunner WH, Wiktor TJ, et al. Characterization of an antigenic determinant of the glycoprotein that correlates with pathogenicity of rabies virus. Proceedings of the National Academy of Sciences 1983; 80(1): 70-4

17. Hassan B, Chokri B, Pierre P, et al. Evidence of two Lyssavirus phylogroups with distinct pathogenicity and immunogenicity. Journal of Virology 2001; 75(7): 3268-76.

18. Real LA, Henderson JC, Biek R, et al. Unifying the spatial population dynamics and molecular evolution of epidemic rabies virus. Proceedings of the National Academy of Sciences of the United States of America 2005; 102(34): 12107-11.

19. Badrane $\mathrm{H}$, Tordo N. Host switching in Lyssavirus history from the Chiroptera to the Carnivora orders. Journal of Virology 2001; 75(17): 8096-104.

20. Gong $W$, Jiang $Y, Z a ~ Y$, et al. Temporal and spatial dynamics of rabies viruses in China and Southeast Asia. Virus Research 2010; 150(1): 111-8.

21. Dong-Kun Y, Youn-Nam P, Gyeong-Soo H, et al. Molecular characterization of Korean rabies virus isolates. Journal of Veterinary Science 2011; 12(1): 57-63.

22. Pant GR, Lavenir R, Wong FYK, et al. Recent emergence and spread of an Arctic-related phylogenetic lineage of rabies virus in Nepal. PLoS Neglected Tropical Diseases
2013; 7(11): e2560.

23. Cherian S, Singh R, Singh KP, et al. Phylogenetic analysis of Indian rabies virus isolates targeting the complete glycoprotein gene. Infection, Genetics and Evolution 2015; 36: 333-8.

24. Reddy RV, Mohana Subramanian B, Surendra KS, et al. Rabies virus isolates of India - Simultaneous existence of two distinct evolutionary lineages. Infection, Genetics and Evolution 2014; 27: 163-72.

25. Dean DJ, Abelseth MK, Atanasiu P. The Fluorescent antibody tests. In: Meslin FX, Koprowsky H, Kaplan MM, eds. Laboratory techniques in rabies. World Health Organization, Geneva 1996. $4^{\text {th }}$ ed., pp.88-95.

26. Orłowska A, Żmudziński JF, et al. Molecular epidemiology of rabies virus in Poland. Archives of Virology 2014; 159(8): 2043-50.

27. Hall TA. BioEdit: a user-friendly biological sequence alignment editor and analysis program for Windows 95/98/NT. Nucleic Acids Symposium Series No. 41, 1999. Information Retrieval Ltd., c1979-c2000, London.

28. Tuffereau C, Bénéjean J, Blondel $D$, et al. Low-affinity nerve-growth factor receptor (P75NTR) can serve as a receptor for rabies virus. EMBO J 1998; 17(24): 7250-9.

29. Nadin-Davis SA, Turner G, Paul JPV, et al. Emergence of Arctic-like rabies lineage in India. Emerging Infectious Diseases 2007; 13(1): 111.

30. Saito M, Oshitani H, Jun Ryan C, et al. Correction: genetic diversity and geographic distribution of genetically distinct rabies viruses in the Philippines. PLoS Neglected Tropical Diseases 2013; 7(7): 10.

31. Bourhy H, Kissi B, Audry L, et al. Ecology and evolution of rabies virus in Europe. Journal of General Virology 1999; 80(10): 2545-57.

32. Takayama-Ito $\mathrm{M}$, Ito $\mathrm{N}$, Yamada k, et al. Multiple amino acids in the glycoprotein of rabies virus are responsible for pathogenicity in adult mice. Virus Research 2006; 115(2): 169-75.

33. Takayama-Ito $\mathrm{M}$, Ito $\mathrm{N}$, Yamada k, et al. Region at amino acids 164 to 303 of the rabies virus glycoprotein plays an important role in pathogenicity for adult mice. Journal of Neurovirology 2004; 10(2): 131-5.

Date of Submission: 2018-06-26 Date of Acceptance: 2018-06-28 